\title{
ARTE, TECNOLOGÍA, GÉNERO Y ESPACIO PÚBLICO. UN ANÁLISIS A TRAVÉS DE LAS OBRAS DE JENNY HOLZER Y BÁRBARA KRUGER
}

\author{
ART, TECHNOLOGY, GENDER AND PUBLIC SPACE. \\ AN ANALYSIS THROUGH THE WORKS OF JENNY HOLZER AND BARBARA KRUGER
}

\author{
María Laura Gutiérrez \\ (CONICET/IIGG)
}

\begin{abstract}
RESUMEN
El presente ensayo busca dar cuenta de las relaciones entre el campo de la estética y el de los estudios de género a partir de la articulación de diferentes intervenciones artísticas y los lenguajes multimediales, un debate que sigue siendo crucial para los feminismos del siglo XXI. En primer lugar, se abordará una breve contextualización sobre la relación entre las prácticas artísticas y la crítica a las identidades sexo-genéricas. En segundo lugar, se incluirán algunos de los debates y relaciones entre los usos de algunas plataformas tecnológicas y las intervenciones artistas, así como la relación que tuvo para estas prácticas artísticas feministas em la construccion de sentidos. Luego, se abordan estos temas en el trabajo de dos artistas contemporáneas: Bárbara Kruger y Jenny Holzer quienes utilizan las intervenciones estéticas asociadas a las plataformas tecnológicas para construir imágenes que intervengan los entramados de configuraciones sociales y sexuales del orden simbólico vigente en nuestra cultura, así como algunos de los modos de producción y recepción aún vigentes de la Institución Arte (Burger, 1979). Ambas se caracterizan por sus modos de producción artística y sus intervenciones en grandes capitales urbanas durante los años '80, fundamentalmente, a partir de la proyección en grandes espacios públicos y la apropiación del lenguaje de los medios de comunicación y el marketing para reconfigurar algunos de sus significados hegemónicos. Por último, no se pretende seguir estrictamente un método que nos conduzca a un análisis semiótico específico de la imagen, o a una semántica de la imagen sino aportar al campo de la comunicación desde um análisis interpetativo y crítico acerca de los modos en que la construcción de conocimiento desde la práctica estética aporta a las Ciencias Sociales y puede generar sentidos que ayuden a discutir la construcción de las significaciones genéricas.
\end{abstract}

Palabras clave: arte, género, tecnologia, espacio público

\section{ABSTRACT}

The aim of this essay is to account for the relationship between the field of aesthetics and that of gender studies taking as starting point the articulation of artistic interventions with multimedia languages, still a compelling issue for feminism, even in the 21 st century. First, we will provide a brief contextualization of the relationship between artistic practices and sexual-gendered identities. Second, we will present some of the debates and linkages between the uses of technological platforms and artistic interventions, together with the importance these feminist artistic practices had in the social construction of meaning.

These themes will be then addressed in the work of two contemporary artists: Barbara Kruger and Jenny Holzer who use aesthetic interventions associated with technological platforms to make images that intervene the framework of social and sexual configurations of the symbolic order in our culture. In this context, the modes of production and reception that are still in place in Art (Burger, 1979) will be also pointed out critically. Both artists 
share similar modes of artistic production and made artistic interventions in big cities during the 1980s, specifically, making projections in large public spaces and appropriating the language of the media to reconfigure its hegemonic symbolic meaning.

Finally, it is worth mentioning that we do not intend to strictly follow a methodology that might leads us to a specific semiotic analysis of the image or to a semantics of the image but rather, to contribute to the field of communication from an interpretative and critical analysis on the ways in which the construction of knowledge derived from aesthetic practices may contribute to the Social Sciences and can generate meanings that help discuss the construction of gender.

Keywords: art, gender, tecnology, public space.

\section{Introducción}

Durante la década del ' 70 en las principales ciudades de Estados Unidos muchas artistas comenzaron a realizar diferentes intervenciones críticas acerca de la conformación del cánon estético, analizando los modos en que histórica y socialmente se había relegado a las mujeres en la participación de la construcción hegemónica de la historia del arte. Las primeras intervenciones feministas se encargaron de confrontar los discursos dominantes sobre el arte, sobre las nociones aceptadas del artista, de genio, y de la propia narrativa histórica del arte que excluía las producciones realizadas por mujeres como "arte menor". En un contexto de luchas de los movimientos juveniles, el black power y los movimientos chicanos, las luchas feministas y del movimiento de mujeres dieron auge a la discusión, la crítica y las propuestas de nuevos conceptos y nuevas perspectivas, también en la historia del arte. en esta disciplina, podríamos decir rápidamente, que estas críticas se articularon en tres grandes ejes:

A) Los análisis que recuperan cronológica e historiográficamente el hacer de las mujeres artistas. Estas primeras indagaciones, que datan de la década de los años 70 en EEUU, con autoras como L. Nochlin ([1972]1988), A. Sutherland (1975) o L. Lippard (1976) buscaban explicar el marco ideológico a través del cual se constituyó y consolidó el campo del arte occidental moderno, exluyendo la práctica artística realizada por mujeres.

B) El abordaje de las producciones de las artistas mujeres en base a sus experiencias corporales, sexuales y genéricas, donde se destacaron los trabajos de J. Chicago ([1977]2007), G. Ecker (1986), W. Chadwick, (1990) o K. Deepweel (1995), M. Garrard y N. Broude (1994), H. Robinson (1987), sólo por citar algunas.

C) La denominada "diferenciación del canon" (Pollock, 1983) que pretendía una trasformación teórica y metodológica de la historia del arte. Estos análisis buscaban un cambio de perspectiva acerca de lo que se había entendido por historia del arte o campo artístico y cultural. No aspiraban a ser un apéndice o suplemento de una teoría más general de la historia del arte o de la crítica cultural, sino ser parte de una trasformación general de las disciplinas. Aquí se destacan autoras como G. Pollock, 1999, 2003, 2010, G. Pollock y R. Parker (1983), P. Mayayo, 2001.

A pesar de este debate interno, podemos decir que durante esos años el trabajo artístico en esas ciudades centrales - como capitales constructoras de hegemonía en torno a las prácticas artísticas y su relación con el feminismo- se centró en la afirmación y reivindicación del cuerpo femenino y la experiencia femenina. Aun com sus diferencias, podemos mencionar a Judy Chicago, Martha Rosler, Carole Schneeman, Lucy Lippard o Ana Mendieta.

Ya entrada la década del ' 80 este modo de asumir el cuerpo femenino se torna uno de los ejes más importantes de debate al interior de la práctica artística en sus cruces con los feminismos críticos com la identidad universal de la experiencia "mujer". En este contexto, las críticas -teóricas, artísticas y políticas- se produjeron en torno a dos ejes claves: la crítica de las lesbianas feministas, que discuten la homofobia del propio movimiento que presuponía la experiência genérico-sexual de las mujeres 
bajo parámetros heterosexuales. Y la crítica de las feministas negras que discutieron las actitudes xenófobas y de clase, también poniendo en jaque la noción de universalidad de la identidad y experiencia de la(s) mujer(es). En este entramado, el arte se constituye, como un campo de disputa de las representaciones en torno a estos debates y experiencias.

Si el cuerpo, -clave en el proceso de subjetivación- había sido el soporte de las indagaciones de los '70, durante los años '80 se produce otra insistencia. Antes que indagar en torno a una identidad feminina que atravesaría las experiências de las mujeres (por el hecho de ser mujeres), las artistas buscaron discutir los roles socio-culturales de masculinidad y feminidad. La insistencia en la reafirmación per se de la experiencia corporal unívoca, dejaba inconclusa la crítica a los estereotipos culturales sexo-genéricos que cristalizados en la sociedad. Así, durante estos años, las estratégias de intervención de las obras tratan de no reducir sus representaciones a la denominada "iconografía vaginal" (que asociaban muy rápidamente mujer a cuerpo) e indagan en torno a otras representaciones posibles de la experiencia de las mujeres. El fotomontaje de Barbara Kruger -que analizaremosresume contundentemente este debate: "tu cuerpo es un campo de batalla". Son, justamente, esas representaciones que construyen el cuerpo las que se transforman en el campo de batalla de las artistas de los' 80.

Por su parte, las estratégias artísticas a través de las cuales se llevan adelante también son resignificadas a partir del lugar de intervención pública en las calles. Alejadas de las galerías y museos buscaron otros escenarios de circulación de las manifestaciones estéticas para criticar los circuitos estéticos hegemónicos. Así la utilización de diferentes elementos del arte menor se articula con la cultura de masas. Este gesto será propicio para las artistas a la hora de re-utilizar las imágenes y textos que los medios de comunicación masivos y los productos de consumo disponen en la esfera pública. Además, en las prácticas artísticas -fundamentalmente en los primeros años de la década-, se observa un arte explícitamente comprometido con el feminismo y sus luchas simbólico-culturales.

Por ejemplo, el Group Material, conformado en 1979 y disuelto en 1996, integrado por artistas como Julie Ault, Mundy Mc Laughlin y Tim Rollins, realizaba instalaciones y proyectos públicos alternando diversos soportes y medios en sus intervenciones. Según el manifiesto del grupo -publicado en 1983-, el colectivo, había sido fundado "como respuesta constructiva frente a los insatisfactorios caminos en los que el arte era concebido, distribuido y mostrado a la sociedad norteamericana". De allí que también otro de los integrantes del grupo dijera en 1987 que "se plateaba la necesidad de entender el espacio público, no cómo un lugar de paso sino para congregarse, para crear espacios de discusión, de socialización y de visibilidad" (citado en López Anaya, 2007: 197).

Retomando las críticas de los '70 hacia la categoría de autor, asociada a la de creador/genio como sinónimo de masculino, tomó relevancia la crítica a la idea de originalidad. Las estratégias de producción de muchas artistas intentó socavar aún más el imaginario de genio=creador=masculino a través de la experimentación que permitió la manipulación con las tecnologías digitales, su anonimato y la reactualización de los collages, otorgando nuevos sentidos y significados a la vieja imagen y a la obra artística en sí, a través de la exploración de diversas tecnologías -como ser el Xenon, los fotomontajes o las proyecciones con haces de luces.

La idea de representación también se exploró a partir de la utilización del collage, con la yuxtaposición y superposición de elementos a partir de la facilidad y creatividad que podían aportar los diferentes soportes tecnológicos aplicados al arte. El reciclaje de la publicidad, la fotografía y el video constituyeron el soporte adecuado para indagar en relación a las sustancialización y al lenguaje como constructor de identificaciones en las producciones artísticas.

Las artistas, aprovechando la escena que habían podido instaurar sus predecesoras y contemporáneas, no trataron tanto de discutir los límites y la entrada a los circuitos tradicionales de arte sino más bien recuperar la escena artística como escena pública. La exploración de diferentes experiencias que se apropiaban del espacio urbano, de los pasajes públicos como también la reiterada utilización de los lenguajes de la publicidad, constituyeron el combo de acción de estas experiencias artísticas. En 
muchas de las manifestaciones ${ }^{1}$ estéticas de la época las imágenes de los medios de comunicación, de las publicidades y del marketing se articulaban en otros contextos produciendo sentidos críticos a la ideología androcéntricas de la cual emergían. Los temas clave del feminismo como ser la sexualidad, la identidad, la legalización del aborto y la violencia doméstica, que habían comenzado a discutirse e instalarse en la escena pública y en la agenda política de algunos países, se transformaron en el tópico recurrente de varias artistas que reactualizaron de modo crítico las propias imágenes estereotipadas de las mujeres que circulan en la cultura de masas.

Artistas como Sherrie Levine, Nancy Spero, Mitra Tabrizian, Julie Ault formaron parte de los trabajos de esta corriente que, lejos de pensar la obra de arte como la realización de un/a genio/a, utilizaban las intervenciones artísticas como lugar de exploración y circulación para intervenir en la vida urbana de manera anónima. Las artistas produjeron sus obras en torno a aquello que se consideraba mal arte o, en este caso, "una mala copia" de un arte verdadero, categoría en la que, todavía en los años '80, caían la fotografía, los videos, las videoinstalaciones, los fotomontajes, los collages y las intervenciones públicas.

De allí que podamos ver este tipo de estrategias en los trabajos de Kruger, Holzer, Levine o Guerrilla Girls. Estas artistas antes que componer o crear una manifestación artística nueva u original, buscan articular, resignificar imágenes, objetos, textos, que fueron realizados por otros y, sobre todo, que circulan en los médios masivos de comunicación. Tal como expresa Nicolás Bourriaud

\begin{abstract}
Un número cada vez mayor de artistas interpretan, reproducen, reexponen o utilizan obras realizadas (...) insertan sus trabajos en el de otros, contribuyen a abolir la distinción tradicional entre producción y consumo, creación y copia, ready-made y obra original. La materia que manipulan ya no es materia prima [sino que] se trata más bien de inscribir la obra de arte en el interior de una red de signos y significaciones, en lugar de considerarla como una forma autónoma u original. La pregunta artística ya no es ¿Qué es lo nuevo que se puede hacer?, sino más bien ¿Qué se puede hacer con? [Así] aparecen como la figura principal de la cultura contemporánea: incrustaciones de la cultura popular en el sistema del gran arte, descontextualizaciones del objeto hecho en serie, desplazamiento de las obras del repertorio canónico hacia contextos triviales. El arte del siglo veinte es un arte del montaje (la sucesión de imágenes) y del recorte (la superposición de imágenes). (Bourriaud, 2007: 13).
\end{abstract}

La reapropiación y utilización de algo pre-existente como material de trabajo, se volvió una búsqueda reiterada. Nos detenemos entonces en las particularidades de los trabajos realizados por Kruger y Holzer.

\title{
La identidad fragmentada o tu no eres tu misma/o. Acerca de Barbara Kruger.
}

Barbara Kruger (New Jersey, 1945) es quizá una de las artistas feministas estadounidense más influyentes del movimiento artístico de los '80. Es conocida, fundamentalmente, por sus trabajos de fotomontajes e instalaciones gráficas en las calles de Nueva York. Kruger comenzó su trabajo como diseñadora gráfica y periodista de las revistas estadounidenses de moda Madmemoiselle y Vogue, de las cuales reutiliza las imágenes publicitarias (fundamentalmente gráficas) y les agrega oraciones cortas y directas que modifican el sentido original de la iconografía. Éstas técnicas han sido uno de los abordajes centrales a lo largo de todas sus intervenciones públicas.

\footnotetext{
${ }^{1}$ La categoría de manifestación en el arte es utilizada por Peter Bürger en contraposición a la idea de obra de arte. Según el autor alemán, los movimientos de vanguardia, fundamentalmente el dadaísmo, niegan (o al menos se refieren negativamente a) la categoría de obra de arte entendida como una obra orgánica, es decir, como una unidad sin mediaciones de particularidades y generalidad. La obra orgánica pretende, además, una impresión global de "sus momentos concretos, que sólo tienen sentido en conexión con la totalidad de la obra, y remiten siempre, al observarlos por separados, a esa totalidad. Los momentos concretos de la obra vanguardista tiene, en cambio, un elevado grado de independencia y pueden ser leídos o interpretados tanto en conjunto como por separado, sin necesidad de contemplar el todo de la obra" (Burger:1997:136). La idea de armonía entre el todo y la parte quedarían en las obras vanguardistas al menos fragmentada. Así, la obra de vanguardia no produce una impresión general que permita una interpretación del sentido. El concepto de manifestación, también se comprende por el carácter efímero, y no de objetivación permanente, con (y hacia) el espectador que tiene cada intervención y/o puesta en escena.
} 
Comenzó a realizar fotomontajes a fines de la década del ' 70 pero fue entrada la década de los ' 80 donde inundó las calles de Nueva York con fotomontajes, generalmente, realizados en blanco y negro o en tres colores -negro, rojo y blanco- utilizando casi siempre el mismo tipo de letra: Futura Bold Italica. Estos colores y tipografías constituyen uno de los ejes característicos de la artista. Otra de las características reiteradas en sus trabajos es el uso de los pronombres indiferenciados (fundamentalmente el pronombre your) para intentar captar la atención del receptor.

La artista trabaja cada una de sus obras disputando los sentidos en torno a las mujeres desde la discusión de las representaciones y las construcciones socio-culturales sobre la femineidad. En la mayoría de sus posters y fotomontajes utiliza imágenes femeninas que recicla de los periódicos, de las revistas, de los medios audiovisuales como el cine y la televisión, así como de los carteles publicitarios para rearticularlos en otros textos que invierten los significados asignados en un principio. La mujer como objeto de consumo, de la mirada y del deseo del varón o como imagen de venta de productos comerciales es puesta en escena para discutir los imaginarios instituidos en torno al género.

El mundo de Kruger se sustenta en la tríada de representaciones en torno a feminismo-consumismopoder, que articulan temas como el abuso doméstico, los estereotipos de la femineidad, la prostitución y la explotación general de la mujer en las sociedades contemporáneas. Como especifica Owens (1985), lo que están en juego en los fotomontajes de Kruger no es tanto lo que la cultura dice de las mujeres sino los que hace a las mujeres. El fotomontaje Your Body is a battleground (Tu cuerpo es un campo de batalla) que Kruger realizó originalmente en 1989 es uno de los trabajos más conocidos de la artista. El mismo fue realizado para una campaña por el derecho al aborto en Estados Unidos y se concibió como afiche callejero y para reproducirse en revistas y periódicos locales.

El fotomontaje está realizado con la base de un rostro de mujer - una cara típica de imagen de revista de moda-dividido en dos grandes mitades, una en tonos grises impresa en positivo, la otra mitad está impresa en negativo. Sobre el rostro de la mujer estaba la frase Your Body is a Battleground, en letras blancas con fondo rojo. En letras más pequeñas se podía leer "apoyo al aborto, control de la natalidad y derechos de la mujer" (ver imagen 1).

En este fotomontaje - a la par que reclama el derecho de la mujer sobre su cuerpo- Kruger reutiliza las imágenes canónicas produciendo un efecto que podríamos enunciar cómo espectral, un rostro que estaba destinado a ser tapa de revista o ubicado como objeto de consumo para la mirada masculina, reapropiado a un cuerpo de sí y para sí. Así mismo la división en el rostro podría ser interpretada, según Jenni Drozdek (2006), a partir de la división entre lo público y lo privado, entre lo interior y lo exterior, entre lo velado y lo desvelado -tal la característica del negativo fotográfico-. La utilización de la iconografía de la cultura de masas, el tipo de letra utilizada de alto impacto, así como la interpelación producida por la frase principal a través del pronombre your, intenta interpelar a quien lee el texto a partir de ese $t u$. En otras de sus manifestaciones, Kruger no sólo reactualiza el collage, o el fotomontaje, sino que se sirve de las instalaciones y los espacios públicos de las grandes metrópolis y sus formatos de circulación y consumo masivos, como ser tazas, remeras, bolígrafos, etc.

Por ejemplo, en la instalación que Kruger realizó en 1991 en la Galería Mary Boone de Nueva York la artista cubrió todas las paredes, el techo y el suelo con imágenes y textos aparecidos en diários que reporducían diferentes estereotipos culturales. Se detenía explicitamente sobre la violencia contra las mujeres, las diversidades étnicas y sexuales. El espacio en el que se debía recorrer la sala era un espacio envolvente que rodeaba al espectadxr, donde no había ningún hueco de pared blanca. Se observan, de fondo, dos rostros de mujeres atravesado por el texto "toda violencia es la ilustración de patéticos estereotipos" (ver imágenes 2 y 3). En relación a este trabajo con los medios de comunicación masivos, la artista expresa que:

Vivimos en un mundo bombardeado con imágenes y sonidos y para algunos de nosotros ha sido una actividad interesante el pensar cuáles serían los significados de esas imágenes y esos sonidos más que recibirlos pasivamente, puesto que de ningún modo somos inmunes a ellos. Pero parte de mi tarea es jugar con las posibilidades de los significados, la multiplicidad de posibles lecturas en cada imagen, en cada texto (...) Veo mi práctica como un tipo de comunicación, entonces: ¿por qué coartar una manera de 
comunicar mientras la realizo? Las palabras son poderosas, y las decimos todo el tiempo, entonces: ¿por qué no hacer uso de ese medio? Me interesan más las preguntas que las respuestas. Todo el mundo tiene respuestas, y yo creo que es más productivo y atractivo para mí pensar sobre preguntas y dudas (citado en Kurcfeld, 2002 [en línea]).

Sin embargo, algunas artistas feministas de la década del '90 acusaron al arte de Kruger de estetizar el sistema antes que de producir una crítica al mismo y a los sistemas de representación del cuerpo y el género. Pero tal como expresa la propia artista "trato de poder participar utilizando métodos que son a la vez seductores y críticos" (ibidem). Aunque su eficacia depende de los contextos de recepción y de los sujetos, las producciones de Kruger discuten en torno a las representaciones sobre los estereotipos socio culturales. Así mismo sus técnicas de artificialidade pop en sus fotomontajes resignifican las prácticas legitimadas del gran arte y desbordan las líneas divisorias entre arte y cultura de masas. En este sentido, tal como lo expresa la propia Kruger, "el arte es todavía un sitio para la resistencia y para la narración de diversas historias, para validar determinadas subjetividades que, normalmente, pasamos por alto" (ibidem).

El fotomontaje You are not yourself, (ver imagen 4) realizado en 1982, quizá sea paradigmático en estas apropiaciones de la representación y la identidad por fuera de una esencia específica de ser mujer. La interpelación a partir de una imagen fragmentada (un espejo roto) señala una ruptura, una fragmentación en la identidad que hace hincapié en que la unidad y solidez del yo es imaginaria, una ficción. El fotomontaje está realizado a partir de la imagen de una mujer reflejada en un espejo pero que se ha partido en pedazos. Es interesante la escena construida por la artista porque, que se apropia de la imagen del espejo -aquél objeto que debería reflejar o devolver una imagen sin fisuras-, pero que queda desecha ante la sentencia de Tu no eres tu mismo/a. Además, no es menor que la mujer -eterno objeto observado, imagen representada a través de la mirada de los otros-, se encuentre en pedazos, no reflejada.

En el mismo sentido se inscribe el fotomontaje We are not what we seem (ver imagen 5), nunca somos aquello que vemos. Se puede interpretar una doble inquietud en él. Por un lado, la puesta en discusión con la idea de una identidad original y común de todas las mujeres. En contraposición a la unidad, el espejo nos devuelve fragmentos de imágenes, fragmentos de una identidad de lo que creemos ser y no somos. Por otro lado, también se puede pensar en torno a la construcción de identidad y el debate en torno a la intersubjetividad de esos procesos, evitando las asociaciones en relación a una supuesta identidad fija o esencial.

En síntesis, utilizando las mismas imágenes que los medios gráficos y audiovisuales reproducen como estereotipos genéricos bajo los formatos de la publicidad y la propaganda, Kruger reutiliza esas mismas herramientas para devolverle al sistema la poca neutralidad de su mensaje. Lo hace, además, en los mismos objetos de consumo que el sistema introduce en el mercado. Artículos como remeras, carteles de publicidad, tazas, biromes, tapas de cds de diversas bandas de rock, como también las tapas de las revistas Esquire o Neesweek (ambas en 1992), son algunos ejemplos significativos. La resignificación de las imágenes y los clichés que histórica y socialmente se han asumido (y consumido), se agolpan en la memoria de los espectadores e interpela a reflexionar sobre el mensaje que, a simple vista, podrían haber interpretado y asumido. Las frases cortas e insistentes golpean una y otra vez en busca de alguna duda que permita pensar acerca de lo que se da por sobre entendido.

\section{Sobre la palabra irónica o "el romanticismo se inventó para manipular a las mujeres". Acerca de Jenny Holzer}

Jenny Holzer (Ohio, 1950) es una artista conceptual con una proyección internacional quizá mayor que la de Kruger. Ha realizado instalaciones públicas en Inglaterra, Estados Unidos, Suiza, Alemania, Italia, Brasil y Argentina, entre otros. A diferencia de Kruger, Holzer hace hincapié exclusivamente en la palabra como medio de expresión de sus manifestaciones estéticas apelando al uso de las tecnologías de proyección. Utiliza, casi exclusivamente, el espacio público como materia/escenario de 
sus proyecciones. Desde los ' 80 sus trabajos se han desarrollado articulando la instalación pública y el lenguaje, sumado a la circulación a través de la red de internet en los últimos años.

En sus primeros Truisms ${ }^{1}$, elaborados entre 1978 y 1983, la artista desarrolla el estilo que la caracteriza (ver imagen 6). Los Truisms se caracterizan por ser aforismos o afirmaciones cortas e irónicas sobre las condiciones sociales de la vida cotidiana de los Estados Unidos, sobre la vida sexual y la violencia. Holzer recure constantemente a la ironía y a la contradicción entre Truisms y Truisms aún en temas como el feminismo, la acción política, el consumo, la religión o las acciones diarias de los individuos. En relación a sus Truism, Holzer dirá que "son un muestreo representativo de opinión. No quise hacer piezas didácticas o dogmáticas (.) quise destacar aquellos pensamientos y asuntos que polarizan a la gente" (citado en Drozdek, 2006).

En esos primeros trabajos Holzer utilizó papeles y carteles con diversas frases anónimas -al estilo de los refranes populares-, que ella misma mecanografiaba y pegaba en las ciudades de Nueva York, en lugares como cabinas telefónicas, parquímetros automáticos o galpones abandonados com visibilidad particular em la ciudad (ver imágenes 7 y 8). También utilizaba autoadhesivos, remeras y carteles realizados en offset, cuya recepción popular se vio impulsada a partir de la respuesta que se fueron colocando debajo de cada una de las frases a modo de intervención espontánea.

Posteriormente, Holzer realizó otra serie similar a los Truisms, pero denominados Inflammatory Essays (ver imágenes 9 y 10). A diferencia de las frases cortas, eran una serie de ensayos de cien palabras, en 20 líneas cada uno, que, originalmente, fueron presentados como una obra pública. Los ensayos estaban impresos en posters callejeros que, semana a semana, eran pegados en paredes de la ciudad de Nueva York. Conservando el mismo formato de escritura, cada ensayo era impreso en un papel de color fluorescente diferente, lo cual producía una atracción visual para detenerse a leerlos. Muchos de los Truisms comenzaron siendo una parodia a las grandes ideas del mundo occidental americano, presentando las frases como si fueran una "refrán", un pensamiento del propio sentido común, pero marcando la ironia para resignificar o producir otro sentido al esperado. Los Truisms de Holzer tomaron relevancia pública en 1982 cuando proyectó sus frases en una de las vallas electrónicas del Times Square de Nueva York. Mientras los espectadores observaban los clásicos anuncios publicitarios de las grandes marcas, la artista intercaló Truisms (que contenían el mismo anonimato y el mismo formato que cualquiera de las publicidades anteriores) con frases como "protégeme de lo que quiero" o la frase, puesta en el corazón de Manhattan, que decía "la propiedad privada creó el crimen" (ver imágenes 11 y 12).

A partir de la segunda mitad de los años '80 los Truisms que Holzer proyectó, se produjeron, casi exclusivamente, a partir del Xenon y el LED ${ }^{2}$ como soportes visuales. Este modo de producir mensajes -característico de sus intervenciones- sirve para proyectar en carteles de grandes eventos de la ciudad newyorkina, como el Times Square, o en carteles de anuncios de aeropuertos, bancos o bolsas de comercio de diversas ciudades del mundo. De a poco las manifestaciones de Holzer se hacen masivas y su técnica de proyección se torna una característica central en su trabajo. Utilizando un lenguaje articulado entre la propaganda y la publicidad, concreto y aforístico, más similar a un eslogan político o publicitario que a una frase intelectual los Truisms de Holzer se caracterizan por su continua búsqueda de una interpelación al espectador allí donde el consumo y la publicidad parecerían ser la imagen indicada. El llamado de atención a través de los modos iconográficos y su posterior disrupción a través del lenguaje es un elemento clave de sus producciones.

\footnotetext{
${ }^{1}$ Las traducciones de Truisms pueden variar como evidencias, tópicos, perogrulladas, axiomas, lugares comunes, etc. Debido a esta dificultad del sentido mantendremos el original dado que, además, así se llama esa serie de las obras de Holzer. Aun así se considera que aquellas traducciones que hacen énfasis en la ironía del término podrían ser las más adecuadas.

${ }^{2}$ El Xenon es uno de los llamados 'gases inertes' utilizados para producir haces dispositivos emisores de luz, como ser los flashes fotográficos o las lámparas de tubos eléctricos. El LEDs (Ligth emitting diode) es un semiconductor de energía que emite haces de luz que sirve para proyectar en grandes espacios y en colores que pueden ser rojo, verde, azul o amarillo. Holzer los utiliza para producir textos sobre diversos escenarios como edificios, montañas, ríos, etc
} 
Tal como lo expresa la artista: "no elegí los carteles electrónicos por ser nuevos, ni siquiera en el comienzo. Hace diez años eran relativamente novedosos, pero sólo eran producto del desarrollo de una tecnología que ya tenía cuarenta años: esa que se usaba para pasar noticias en un cartel gigante ubicado en el Times Square neoyorquino. Decidí usarlos porque creo que son el medio perfecto para transportar el tipo de información que quiero transmitir" (citado en Graña, 2000 [en línea]). También expresa que prefiere usar ese tipo de proyectores dado que permiten el puro anonimato, permitiendo la trasmisión del "contenido" ("lo que sea que eso quiera decir", aclara). Holzer dice que, si bien los LEDs son, actualmente, la forma habitual en la que se transmite la información bursátil y publicitaria es justamente eso lo que hace aumentar aún más el contraste de los contenidos que introduce en la discusión pública. Y afirma que "lo que puede llamar la atención de la gente, tanto en la calle como en una galería o museo, es la fuerza de los textos. Para mí, lo importante es descubrir qué es lo que hace que la gente pare y mire fijo algo".

Sin embargo, para la artista no sólo es importante la frase que proyecta sino el edificio, el monumento o el espacio público en el que las proyecta, dado que la fuerza simbólica de cada uno de los edificios que elige construye también el sentido de la ironia de los Truisms, la elección no es ni azarosa, ni ingenua. Ha proyectado en edificios de ciudades tan diversas como Roma, Venecia, Río de Janeiro, Oslo, París, Burdeos, Berlín, Washington, Miami, Nueva York y Buenos Aires. Como explicita la teórica Rossi Braidotti:

Kruger y Holzer son ejemplos perfectos de apropiaciones postmodernas, incisivas y exentas de nostalgia de los espacios urbanos públicos con fines creativos y políticos. En sus manos, las ciudades como área de tránsito y paso se convierten en un texto, un espacio para la significación, repleto de señales y carteles que indican múltiples direcciones posibles, y a los que el artista añade una dirección propia, inesperada y rompedora (Braidotti, 1996, [en línea]).

Entre estos ensayos inflamatorios -y en relación a la ironía crítica hacia los estereotipos de género-, podemos mencionar los siguientes fragmentos "el sentimentalismo demora la eliminación de lo políticamente retrógrado y lo orgánicamente defectuoso". "Muerto eres libre! puedes transformar el niño radiante que hay en tí en un reflejo de la mierda que estabas destinado a servir". "Hasta tu familia puede traicionarte". Holzer intenta captar así, en un lenguaje corto y directo, similar al de la publicidad, la atención de los transeúntes de las calles de New York, enfrentándolos, al momento de la lectura, con sus propios estereotipos de familia americana. Pone en debate el lugar del sentimentalismo como característico de la familia y también, como lugar pasivo de la mujer. En cierto sentido, las frases resuenan en otra posterior que es quizá una de sus más conocidas: "el romanticismo se invento para manipular a las mujeres" (ver imagen 13).

Descontextualizando las manifestaciones estéticas de los viejos soportes y poniendo en circulación modos de proyección poco explorados, sus frases de sentido común se trasforman en incisivas ante la poca expectativa de quien observa esperando encontrarse con lo mismo de siempre. De nuevo, junt a Braidotti, podemos decir que "los paneles electrónicos de Holzer, que se hallan en el medio de las ciudades, infectadas/invadida de publicidad trasmiten mensajes extremadamente políticos destinados a despertar nuestras conciencias" (ibidem).

Ahora bien, de esto no se debe deducir que Holzer considere al lenguaje como un mero instrumento, cuya "intención" produzca un "efecto" en el espectador, pues se sabe que las derivas del lenguaje y la recepción estética exceden los límites de la ‘intención’ de quien las produce. En este sentido, la propia artista aclara que:

Mis textos exploran los límites de la tolerancia. Están hechos de múltiples voces, a veces contradictorias. [Es por ello que] muchas de mis frases están hechas en base a muestras, al modo de las encuestas de opinión. Trato de reflejar, sociológicamente, gracias a investigaciones y consultas de archivos y bibliografía, las afirmaciones de los distintos sectores sociales, políticos y económicos en un momento determinado. Los textos suelen hacer visible cierto discurso congelado de la cotidianidad y, por lo tanto, hacen visible también un conjunto de prejuicios. La escritura y el lenguaje son estructuras muy fuertes, pero también son lugares donde perderse. Hay una cualidad del lenguaje que construye realidad y al 
mismo tiempo opera sobre la realidad. Pero no busco ni pretendo tener fórmulas para lo que debe ser una obra de arte (citado en Lebenglik, 1999 [en línea]).

Por último, no podemos dejar de mencionar uno de sus proyectos actuales que se desarrollan a través de internet, Please Change Beliefs. Se basa en la interacción con los cibernautas a partir de la creación de diferentes Truisms en base a uno que coloca la artista en la web. Estos gestos forman parte de las indagaciones de la artista en torno al anonimato y la circulación de su propio trabajo como apropiación de multiples, por fuera de la originalidad y la firma individual de creación. La explícita intención del trabajo de Holzer en modo anónimo e interactivo (tanto en la proyección como en la web) critica ese lugar de la autoría. En este sentido, la apropiación colectiva se profundiza y se trasforma en un potencial específico en los trabajos tanto de Holzer como de Kruger.

\title{
Conclusiones. Reinventar la identidad en las palabras
}

Como se dijo el trabajo de muchas artistas comenzó a indagar fuertemente no ya desde una asunción y reivindicación de lo femenino sino, más bien, desde las representaciones y estereotipos genéricos en su conjunto. Este giro se realizó, en parte, por la asunción de los problemas en relación al lenguaje que las artistas habían comenzado a explorar y, en parte, porque la propia noción de mujer como esencia monolítica no podía ser asumida ya sin un largo debate sobre sus consecuencias. Como expresa Ergas

\begin{abstract}
El sujeto femenino, cuyo yo las feministas reconstruían en la praxis de la separación y la distinción y reconquistaban en las campañas a favor de la autoposesión femenina, mostró su fragilidad. En su sentido de sujeto unitario, el término mujer resultaba sistemáticamente socavado por la propia insistencia feminista en el cuestionamiento de la naturaleza de dicho sujeto, en el divorcio entre anatomía y destino y por el énfasis que ponían, no sólo en las diferencias que distinguen a las mujeres de los hombres, sino también en las semejanzas, e incluso en las identidades entre hombres y mujeres (Ergas, 1993: 175).
\end{abstract}

Las ideas de una supuesta identidad colectiva y común a todas las mujeres comenzaban a ser puestas en entredicho y la afirmación del cuerpo de la mujer como objeto crítico de las representaciones vigentes comenzaba a relegarse en pos del cuestionamiento y las indagaciones en la construcción de identidad a través del lenguaje.

En este marco fue fundamental la discusión en torno a las imágenes que se re-producían a través de los medios masivos de comunicación, que representaban a las mujeres como lugar de la representación desde y por la mirada androcéntrica. Estas exploraciones en torno a la identidad se vuelven un eje central en la discusión del movimiento feminista. Como se preguntan Seylha Benhabib y Drucilla Cornell, “¿Como se puede basar la teoría feminista en el carácter único de la experiencia femenina sin reificar con ello una solo definición de la femineidad haciéndola paradigmática, esto es, sin sucumbir a un discurso esencialista sobre el genero?" (Benhabib; Cornell, 1990: 26). Si la iconografía vaginal fue uno de los ejes fundamentales en los '70, estas artistas que analizamos vieron en el lenguaje una de las claves para interpelar la construcción de las identidades genéricas.

El análisis en torno al lenguaje comenzó a ser vital para las prácticas feministas artísticas pensándolo como un sistema constructor de significaciones a través del cual

Se construye el sentido y se organizan las prácticas culturales y según el cual, la gente representa y entiende el mundo, incluye la propia identidad y la relación con otro. En este sentido el análisis del lenguaje provee un punto crucial de entrada, un principio desde el cual se comprende cómo se conciben las relaciones sociales y por lo tanto (...) cómo se organizan las instituciones, cómo se experimentan las relaciones de producción y cómo se establece la identidad colectiva (Scott, 1990: 2).

El debate en torno a la idea de igualdad vs. diferencia que se sostenía durante los '70 intenta pensarse y desarticularse a partir de desarticular el pensamiento binario que lo constituye y que reproduce las asignaciones del androcentrismo existente asociadas, a un lado, con lo femenino y, a otro, con lo masculino. De allí que se intenten pensar las diferencias sexuales, genéricas, de deseos y las subjetividades como condiciones de identidades colectivas e individuales, como negación constante de la fijación de las identidades. Tal como expresa Owens en relación a los collages de Kruger: 
La disposición de la obra de Kruger es siempre específica en cuanto al género; sin embargo, su sentido, no es que la masculinidad y la femineidad son posiciones fijas asignadas previamente por el aparato representacional, sino que Kruger utiliza más bien un término sin contenido fijo, los transportadores lingüísticos (yo/tu), a fin de demostrar que las identidades masculina y femenina no son en sí estables, sino que están sometidas a intercambio (Owens,1987: 121)

Las manifestaciones de las artistas cruzan el umbral de la reafirmación corporal para preguntarse en torno a los modos en que las imágenes -aquellas que construyen una recepción androcéntrica-, pueden ser reinscriptas en una crítica a los cánones vigentes. Como decía Teresa de Lauretis:

Quienquiera que defina el código o el contexto, tiene el control...y todas las respuestas que acaten ese contexto renuncian a la posibilidad de redefinirlo. [pero] no hay porqué pensar que el lenguaje y las metáforas pertenezcan a alguien. El lenguaje y las metáforas están siempre en la práctica, en la vida real, donde reside en ultima instancia el significado (...) pues ¿de qué otro modo podrían proyectarse los valores sociales y los sistemas simbólicos en la subjetividad si no es con la mediación de los códigos (la relación del sujeto en el significado, el lenguaje, el cine) que hacen posible tanto la representación como la auto representación? (De Lauretis, 1992:13).

Por otra parte, -y desde un marco diferente al de De Lauretis-, Nancy Fraser $(1997)^{1}$ hace un aporte que resulta relevante para pensar la importancia del lenguaje en las construcciones sociales de género y de las experiencias artísticas. La teórica norteamericana se pregunta ¿qué buscan las feministas en una teoría del discurso? Y se contesta que una concepción del discurso puede ayudar a entender al menos cuarto cosas: 1.- Cómo se construyen (discursivamente) las identidades sociales de las personas y cómo se modifican con el transcurso del tiempo. Entendiendo las identidades sociales como complejos de significados, redes de interpretaciones signadas por las prácticas sociales históricas específicas y modificables (no esenciales) en el tiempo.

2.- Cómo, bajo condiciones de desigualdad, se forman y desintegran los grupos sociales, entendidos como agentes colectivos.

3.- Como se asegura y se convierte la hegemonía cultural de los grupos dominantes dentro de la sociedad.

4.- Como se puede echar luz sobre los proyectos de cambio social y sobre la práctica política, intentando discutir el supuesto "incapacitante" de que las mujeres son simples victimas pasivas de la dominación masculina.

Además, es pertinente retomar la utilización de cierto discurso paródico que se observan en estas manifestaciones, esto es, la utilización del lenguaje como estratégia de resignificación de las propias imágenes. Estas formas de juegos del lenguaje e imágenes han sido propicias para las prácticas artísticas de estas artistas en particular, dado que contribuyen a la crítica de las representaciones y las estrategias de producción establecidas. El uso de ellas está abocado a interpelar las representaciones sexistas y las representaciones genéricas de la cultura dominante.

Así mismo, la distancia propuesta por estas artistas a partir del lenguaje, que resignifica las imágenes utilizadas, pone en discusión los modos de representación que habían sido utilizado por las artistas de la década anterior, la construcción de la identidad como esencia común deja de ser una afirmación para pasar a convertirse en una disputa. Según Hutcheon

\footnotetext{
${ }^{1}$ Fraser se pregunta por las condiciones de posibilidad de formación de un grupo social bajo cierta identidad colectiva (en este caso la de género) como modo de confrontación con el discurso social hegemónico. La teórica norteamericana retoma la categoría de hegemonía de Antonio Gramsci, entendiéndola como la designación de la faceta discursiva del poder. Es decir, "el poder para establecer el sentido común o la doxa de una sociedad, el fondo de descripciones autoevidentes de la realidad sociales que normalmente permanecen inexpresadas. (...) La noción de hegemonía apunta a la intersección entre poder, desigualdad y discurso [y] designa un proceso mediante el cual la autoridad cultural es objeto de negociación y controversia. Presupone que la sociedad contiene una pluralidad de discursos y de lugares discursivos de posiciones y de perspectivas desde las que se habla" (Fraser, 1997: 204).
} 
En el arte feminista, escrito o visual, las políticas de la representación son inevitablemente las políticas de género: la manera en que las mujeres se presentan a la vista de sí mismas, la manera en que los hombres miran a las mujeres, la manera en que las mujeres son pintadas en los medios, la manera en que las mujeres se miran a sí mismas, la manera en que la sexualidad masculina se vuelve fetichismo, los criterios para la belleza física - la mayoría de éstas son representaciones culturales y, por lo tanto, no inmutables, sino condicionadas. Las estrategias postmodernas a menudo son empleadas por artistas feministas para llamar la atención hacia la historia y el poder histórico de esas representaciones culturales, mientras contextualizan a ambos de manera que los deconstruya (1993: 9).

Así una de las potencialidades de las producciones puestas en circulación por ambas artistas es que utilizan los mismos medios de la cultura del mercado y de las imágenes massmediática, pero para rearticular, o resignificar los sentidos dominantes.

Podemos decir que el esencialismo de las primeras obras de reivindicación de lo femenino, o de la reafirmación de la mujer como política efectiva de la representación en las manifestaciones estéticas de las artistas, comenzó a convivir con nuevos modos de entender las representaciones y las identidades que se disputaban. Así mismo, las formas estéticas utilizadas conviven con la interpelación a través del lenguaje como eje clave en la construcción y resignificaciones de la/s identidad/es.

Christopher Reed, citando a Hal Foster, dice que:

Kruger pone en crisis al lenguaje (...) haciendo que la imagen hable al espectador como usted, de manera tal que el significado cambia con cada espectador. Foster alaba a Kruger por rechazar las viejas ideas modernas acerca de la pureza de la estética mezclando lenguajes del yo, del arte y de la vida social, pero instándola a distanciarse de los espectadores que podrían leer el nosotros o el nos como la auténtica voz de la artista, o creer que el poder puede ser nombrado (o) localizado. Denunciando un esencialismo tal, una creencia en que hay esencias más allá o aparte de su representación. (Reed, 1990 [en línea]).

En este sentido, las manifestaciones estéticas a través de la disputa en torno al lenguaje y las imágenes de circulación masiva intentan subvertir las significaciones asociados históricamente a las mujeres desde los medios de comunicación, las industrias del consumo y la propia historia del arte, a saber: la mujer como espectáculo para ser admirada o consumida como objeto de belleza, la mujer como el lugar por excelencia de la sexualidad y el cuerpo para ser contemplado por otros. Kruger y Holzer construyen los collages y las proyecciones no sólo para denunciar explícitamente el poder sino más bien para discutir las nociones arraigadas de deseo, poder y representaciones que se asumen en las imágenes que se reproducen constantemente a través del consumo. Estas expresiones estéticas disputan los sentidos que se significan en y por el lenguaje, por los medios de comunicación y la publicidad (ya sea gráfica, textual, audiovisual, etc.). Además, la búsqueda de otras lecturas e interpelaciones a partir de la utilización de los impersonales yo/tu de los fotomontajes o de las proyecciones, el foco puesto en la disputa de identidades genéricas, la utilización de elementos de la cultura de masas y de los objetos de consumo, se trasforman en uno de los tantos modos de apelar a la sensibilidad y la apropiación de quien lee/observa.

Es relevante la utilización específica de los grandes espacios públicos. Si la entrada a las galerías y la discusión de los modos institucionalizados de circulación del arte fueron algunos de los intentos de las artistas de los '70, durante esta etapa las ciudades se volverán la hoja donde producir la escena artística. La apropiación del espacio público como escenario de las manifestaciones es no sólo reiterada sino una apuesta específica. Siguiendo a Braidotti (1996) las manifestaciones artísticas públicas de Holzer y Kruger son una demostración de utilización de los espacios urbanos públicos con fines creativos y políticos que indican múltiples direcciones posibles y a los que las artistas añaden una dirección propia. Aun en la sobrecarga de imágenes de las grandes metrópolis (algo que podríamos denominar de cierta anestesia visual), los espacios urbanos son reapropiados y las ciudades se convierten en un texto, un espacio para la re-significación de las manifestaciones estéticas anónimas, un modo de ampliar y apropiarse de la esfera publica, de poder hablar, expresar, proyectar con la propia voz. 


\section{Imágenes:}

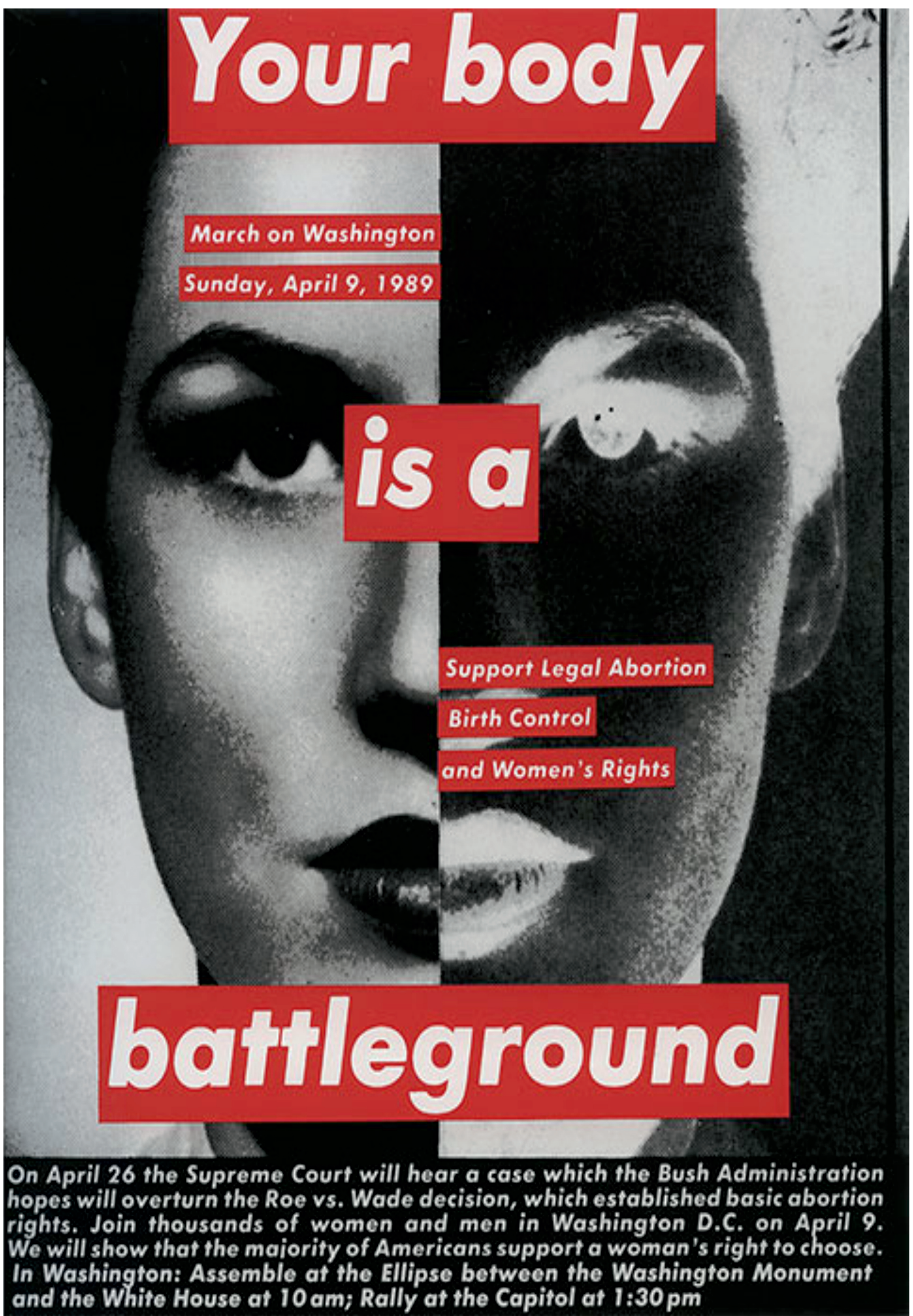




\section{Imágenes referenciadas}

1. KRUGER, Barbara (1989). Untitled (Your Body Is a Battleground). Serigrafía sobre vinilo, recuperada de https://goo.gl/dq7P47

2. KRUGER, Barbara (1991). All Violence is an Illustration of a Pathetic Stereotype, Mary Boone Gallery, NY. Photographic collage, recuperada de https://goo.gl/FZvubK

3. KRUGER, Barbara (1991). All Violence is an Illustration of a Pathetic Stereotype, Mary Boone Gallery, NY. Photographic collage, recuperado de https://goo.gl/FZvubK

4. KRUGER, Barbara (1981). Untitled (You Are Not Yourself). Photograph collage, recuperado de https://goo.gl/BiAo8i

5. KRUGER, Barbara (1988). We are not what we seem. Screen print, vinyl, chassis, recuperado de https://goo.gl/mVQmwR

6, 7 y 8. HOLZER, Jenny (1978). Truism. Recuperado de https://goo.gl/t8FJoe

9. 10. HOLZER, Jenny (1978-82). Inflammatory Essays. Lithograph on paper, recuperado de https://goo.gl/kEEDpe

11. 12 y 13. HOLZER, Jenny (1984-2002). Truism. Projections of LEDs, recuperado de https://goo.gl/qA86dH

\section{Referencias Bibliográficas}

BENHABIB, Seyla y Cornell, Drucilla (ed). Teoría feminista y Teoría Crítica. Ensayos sobre la política de género en las sociedades de capitalismo tardio. Valencia: Ediciones Alfons el Magnanim.

BRAIDOTTI, Rossi (1996). “Un ciberfeminismo diferente.” Recuperado de www.estudiosonline.net.

BOURRIAUD, Nicolás (2007). Postproducción. La cultura como escenario: modos en que el arte reprograma el mundo contemporâneo. Buenos Aires: Adriana Hidalgo.

BÜRGER, Peter (1997). Teoría de la Vanguardia. Barcelona: Península.

DE LAURETIS, Teresa (1992). Alicia Ya no. Feminismo, semiótica, cine. Madrid: Cátedra.

DROZDEK, Jenni (2006). "Looking to the Left: Politics in the Art of Barbara Kruger and Jenny Holzer.” Recuperado de en http://garnet.acns.fsu.edu/ nr03/drozdek.htm, 2006.

ERGAS, Yasmine (1993). "El sujeto mujer: el feminismo de los años sesenta-ochenta." En Duby, George y Perrot, Michelle (edit.). Historia de las mujeres, Tomo 10. Madrid: Taurus.

FRASER, Nancy (1997). Iustitia interrupta. Reflexiones desde la posición “postsocialista”. Bogotá: Siglo del hombre editores.

GOODEVETHE, Thyrza Nichols (1997). "Art of public address. Barbara Kruger. Interview. Cover Story”. Recuperado de http://findarticles.com/p/articles/mi_m1248/is_n11_v85/. 1997.

GRAÑA, Dolores (2000). "Problemas de cartel." En Las 12, Diario Página 12. Recuperado de http://www.pagina12.com.ar/2000.

GUASCH, Ana María (ed.) (2000). Los manifiestos del arte posmoderno. Textos de exposiciones 1980-1995. Madrid: Akal. 
HELLER, Agnes; Feher, Ferenc (1989). Políticas de la postmodernidad. Ensayos de crítica cultural. BARCELONA: Península

HUTCHEON, Linda (julio, 1993). "La política de la parodia postmoderna". En Revista Criterios. La Habana.

KURCFELD, Michael (2002). "Interwiev with Barbara Kruger." Recuperado de http://www.pbs.org/wnet/egg/217/kruger.

LOPEZ Anaya, Jorge (2007). El extravío de los límites. Claves para el arte contemporáneo. Buenos Aires. Emecé.

LEBENGLIK, Fabián (1999). “Aforismo de fin de siglo.” En Radar, Diario Páginal2. Recuperado de http://www.pagina12.com.ar/1999/suple/radar.

OWENS, Craig (1985). "El discurso de los otros: las feministas y el pós-modernismo”. En Foster, Hal (comp). La posmodernidad. Barcelona: Kairós.

REED, Christopher (1993). "La Postmodernidad y el Arte de la Identidad." Recuperado de www.deartesypasiones.com.ar/03/doctrans/Reed-Postmodernidad.

SCOTT, Joan (1994). "Deconstruir Igualdad-versus-diferencia: usos de la teoría posestructuralista para el feminismo". En Feminaria, año VII, N 13. Buenos Aires.

SONTAG, Susan (1984). Contra la intepretación. Barcelona: Seix Barral, 